\title{
An echocardiographic study in patients with palpitations
}

\author{
Arwa M. Fuzi Alsaraf \\ Department of Medicine, College of Medicine, University of Mosul.
}

(Ann. Coll. Med. Mosul 2012; 38 (1): 1-7).

Received: $4^{\text {th }}$ Sep. 2011; Accepted: $8^{\text {th }}$ Apr. 2012.

\begin{abstract}
Objectives: Palpitations (increased or abnormal awareness of the heart beats), often caused by cardiac arrhythmia, anxiety, and non cardiac causes; also caused by non arrhythmic cardiac problems such as mitral valve prolapse (MVP), other valvuler disease, heart failure, cardiomyopathy, and congenital heart diseases (CHD). Some patients had no cause for palpitations.

We aim to study the cardiac problems revealed by echocardiography in patients with palpitations, and the differences between males and females.

Patients and methods: A total of 267 patients who seeked medical advice specifically for palpitations, and another 173 controls, had echocardiography evaluation, results were classified into three groups, MVP, myocardial disease, and valvular and CHD. Statistical analysis using chi- square test was applied.

Results: The patients consisted of 221 (83\%) females, and 46 (36\%) males, aged between 14- 77 years, mean age 38 years. MVP was diagnosed in $76(28 \%)$ patients ( $P$ value 0.019$)$ and it was more significant in females ( $P$ value 0.046). Other valvular diseases and CHD were also considerable causes of palpitations in females ( $P$ value 0.043$)$. Myocardial diseases were diagnosed in $62(23 \%)$ patients, including 15 (33\%) males.

Conclusion: Echocardiography was normal, or minimally abnormal as in MVP in most of patients 189 (71\%). MVP and other valvuler diseases and CHD were significant causes of palpitation in females, while myocardial diseases were more frequent in males. These results are consistent with previous studies.
\end{abstract}

Keywords: Palpitation, echocardiography, mitral valve prolapse, myocardial, valvular and congenital heart diseases.

الخلاصة

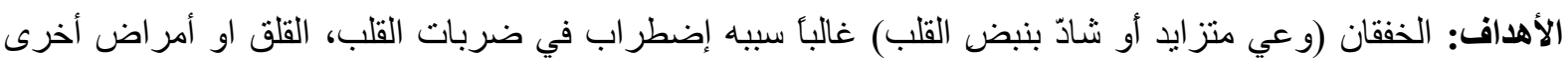

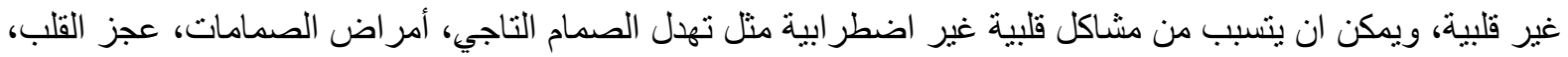

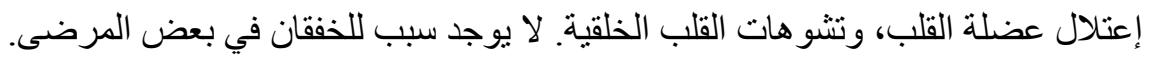

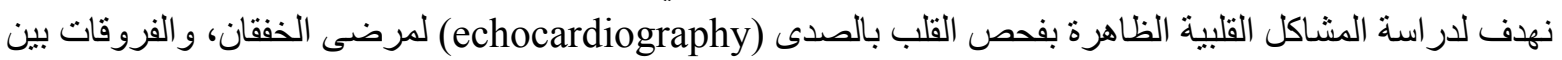
الأكور والإناث.

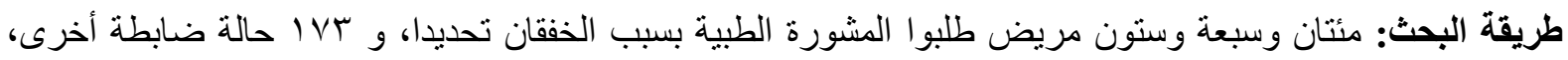

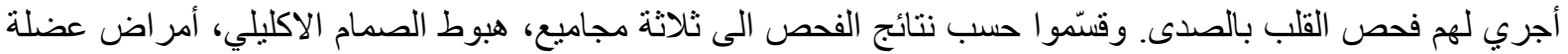

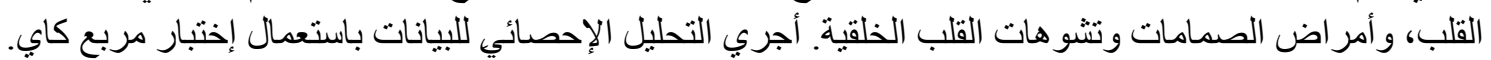

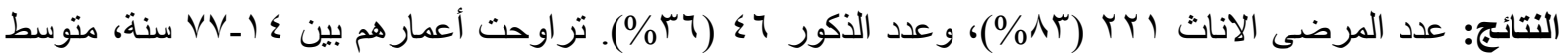

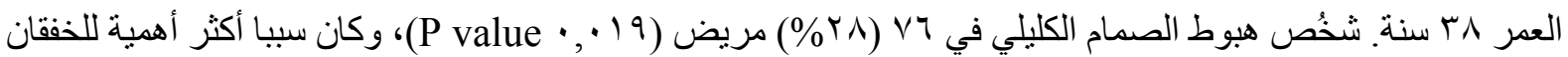




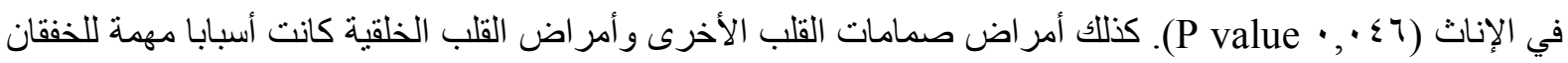

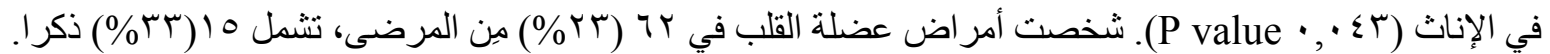

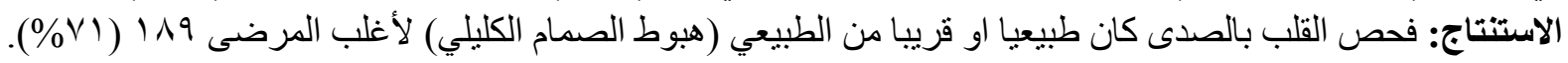

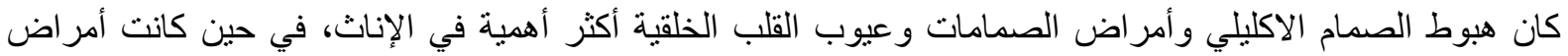

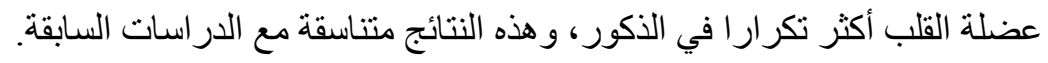

$\mathrm{B}$ $y$ definition palpitation is abnormal, unpleasant awareness of ones own heart beat. This symptom may be brought on by a variety of cardiac disorders, such as cardiomyopathy, heart failure, valvular heart diseases, coronary heart diseases and pericarditis, but the most common cause is primary cardiac arrhythmias ${ }^{(1-3)}$. Several non cardiac disorders such as hyperthyroidism, vasovagal syncope and hypoglycemia may also cause palpitation ${ }^{(1,2)}$. No cause for palpitation can be found in up to $16 \%$ of patients ${ }^{(1,4)}$.

Palpitation is one of the common symptoms for which cardiac patients are referred. It may be the reason for 30 to $40 \%$ of referral to cardiology clinics like dyspnea ${ }^{(3,5,6)}$. Palpitation can either be a physiological expression of normally beating heart or dangerous pathological state of the heart. This makes this symptom unique and warrants careful evaluation.

The heart is a mechanical organ with multiple mobile anatomical structures. There is constant blood flow in multiple directions. Apart from this, the heart has its unique translational, rotational movement. These intrinsic movements combined with proximity to chest wall generate vibratory motion signals. These signals are generally dampened by the encircling pericardial space. The neural signals responsible for perception of palpitation are not clear. If the heart hits against the chest wall it is the somatic nerve from the chest wall that carries the signal. Vibrations generated within the heart chambers and the valves are carried by the myocardial and intravascular autonomic nerves ${ }^{(7)}$.

Historically "Harvey" used the word palpitation in De Motu in reference to a motion of the heart observed in his vivisection studies.
Moving beyond his physiological observation, he expressed awareness that strong emotions have a physical effect on the body manifested in the behavior of the heart: "for every passion of the mind which troubles men's spirits, either with grief, joy hope or anxiety, and gets access to the heart, there makes it to change from its natural constitution, by distemperature, pulsation, and the rest ${ }^{(8,9)}$. "Lower" used the term to describe a symptom complex in a physiological setting, an important distinction. The interdependence of brain and heart is a recurrent theme in Lower's work ${ }^{(9,10)}$.

Approximately $15 \%$ of the general population experience palpitations in a given year ${ }^{(11,12)}$. Palpitations are typically encountered in outpatients settings, reportedly ranking among the top 10 symptom complain of patients attending a general internal medicine clinic ${ }^{(12)}$. Palpitation may be brought on by a variety of cardiac disorders, such as cardiomyopathy, valvuler heart disease, and coronary artery disease, but the most common cause is primary cardiac arrhythmias, several non cardiac disorders may also cause palpitations.

For several decades a widely held belief has existed in some association between MVP and various cardiac symptoms, including palpitations ${ }^{(12)}$. In MVP ( billowing of mitral valve leaflet into the left atrium during systole), although most patients are asymptomatic, some experience nonspecific symptoms (e.g. chest pain, dyspnea, palpitations, dizziness, near syncope, migraine and anxiety), thought to be due to poorly defined associated abnormalities in adrenergic signaling and sensitivity rather than to MVP alone. In about one third of patients, emotional stress precipitates palpitations which may be a symptom of benign arrhythmias ${ }^{(13)}$. Transient MVP may occur when intravascular volume 
decreases significantly as in severe dehydration or during pregnancy when the woman is recumbent and the gravid uterus compresses the inferior vena cava reducing venous return ${ }^{(13)}$.

The resting electrocardiogram should be performed in all patients with palpitation. Obviously, a palpitation is not likely to be "caught" during the brief recording period of an ECG. However the resting ECG provides important clues as to the presence or absence of underlying structural heart disease which can provide a substrate for arrhythmias ${ }^{(12)}$. Exercise testing in patients with palpitations who also have chest pain may help in uncovering evidence of ischemic heart disease, which in turn, might be contributing to the patients' symptoms; also it may induce suspected arrhythmias in patients with palpitations. Holter recording can be helpful in patients who experience their palpitations at least once per day.

Echocardiogram can be very useful in ruling in or ruling out overt structural heart disease.

In our study we aim to verify the echocardiography findings in different patients with palpitations, and to clarify the role of structural heart disease in causing palpitation. The difference between male and female with palpitation in regard to the presence of underlying structural heart disease is also studied.

\section{Patients and methods}

This observational, hospital based, retrospective, case control study began in January 2010 and ended in March 2011. Four hundreds and forty cases and controls aged between 13 and 77 years were involved.

\section{Study sample and data collection}

Two hundreds and sixty seven (267) male and female patients presented with palpitations aged between 14 and 77 years were recruited from outpatient's clinic in Ibn Sina Teaching Hospital in Mosul. Another group of 173 male and female controls, aged between 13 and 70 years, who had echocardiogramphy study for routine checking, preoperative preparation or other non specific symptoms (like chest discomfort, mild dyspnia, atypical chest pain, cardiac neurosis) but without palpitation were collected from echocardiography unit in the same hospital.

Consents of patients were insured, then thorough history was taken including: history of the palpitation described as (heart flips, skipped beats, strong beats, irregular beats, heart thumping, bubble sensation in heart or chest, heart fluttering, racing or rapid heart beats, pounding in chest or neck, heart jumping out of chest and chest shaking) ${ }^{(12)}$, physical examination, electrocardiography study and chest X-ray were performed.

Detailed 2- dimensional, M-mood and Doppler echocardiography study was carried on for all patients and controls. Accordingly, the candidates were classified into 4 groups: those with normal echocardiograph considered as normal, those with MVP (defined as movement of part of either leaflet behind the plane of the annulus in any view other than the 4- chamber view, or the displacement of the point of coaption behind the plane of annulus in the 4- chamber view) ${ }^{(14)}$, considered as MVP group, those with left ventricular (LV) systolic dysfunctions (ejection fraction $<50 \%$ ), diastolic dysfunctions, left or right ventricular hypertrophy, cardiomyopathies and LV segmental wall motion abnormalities were considered as ischemic and non ischemic myocardial diseases MCD group, and valvular heart diseases (excluding MVP) and congenital heart disease considered as $\mathrm{V} /$ CHD group.

\section{Statistical analysis}

Chi - square test was performed to determine the ( $P$-value), $p$ - value $<0.05$ was considered significant. Odd ratio (OR) that is (odds of factor among cases divided by odds of factor among control) was calculated, 1means no risk, >1 means risk, <1 indicates protection. Confidence interval $(\mathrm{Cl})$ was considered for all values.

\section{Results}

A total of 267 patients presented with palpitations were included in the study, age was between 14 and 77 years, with a mean age 38 years (14 SD). There were 221 female 
patients (83\%) and 46 male patients (17\%), female: male ratio 4.8: 1. (Table 1)

One hundred seventy three controls without palpitation were collected aged between 13 and 70 year old; mean age 39 year (12 SD), 111 females (64\%) and 62 males (36\%), female: male ratio 1.8: 1 .

Abnormal echocardiography including MVP was found in 154 patients presented with palpitation (58\%), and in $89(51 \%)$ controls, $\mathrm{P}$ value (0.199), including126 female (57\%), and $28(60 \%)$ males. (Table 2)

MVP was diagnosed in $76(28 \%)$ patients with palpitation, and in $31(17 \%)$ controls, $(\mathrm{P}$ value 0.019$)$. Sixty two patients $(23 \%)$ with palpitation found to have cardiac muscle disease (including ischemic cardiac muscle diseases), compared to 53 (30\%) controls, (P value 0.554). Valvular or congenital heart disease was detected in 16 patients with palpitation (6\%), and in $5(3 \%)$ controls, ( $P$ value 0.095 ). (Table 4)

In other point of view structural heart diseases other than MVP were counted in 78 (29\%) patients with palpitations, 61 (28\%) females and 17 (37\%) males. and in 58 (34\%) of controls. (Table 3 ).

The difference in types of underlying structural heart diseases between males and females was shown in (table 4). MVP and other valvular or congenital heart diseases were the cause of palpitation in $65(29 \%)$ and in $14(6 \%)$ females respectively with a $P$ value (0.046) and (0.043). Myocardial diseases found in $47(21 \%)$ females with palpitation. Ninety five (43\%) females with palpitation had normal echocardiography study.

In males, MVP cause palpitation in $11(24 \%)$ patients, myocardial diseases in 15 (33\%) patients, and other valvular or congenital heart diseases in $2(4 \%)$ patients. Normal echocardiography was found in $26(57 \%)$ male patients.

Table (1): Percentage of male and female in patients and controls.

\begin{tabular}{|l|c|c|c|}
\hline Gender & Palpitation & Control & Total \\
\hline Female & $\begin{array}{c}221 \\
82 \%\end{array}$ & $\begin{array}{c}111 \\
64 \%\end{array}$ & 332 \\
\hline Male & $\begin{array}{c}46 \\
18 \%\end{array}$ & $\begin{array}{c}62 \\
36 \%\end{array}$ & 108 \\
\hline Total & 267 & 173 & 440 \\
\hline
\end{tabular}

$P$ value 0.00

Table (2): Total patients with structural cardiac abnormalities including MVP compared to normal echo study.

\begin{tabular}{|c|c|c|c|c|c|c|c|c|c|c|}
\hline \multirow{2}{*}{ Echo study } & \multicolumn{2}{|c|}{$\begin{array}{c}\text { Palpitation } \\
267\end{array}$} & \multicolumn{2}{|c|}{$\begin{array}{c}\text { Control } \\
173\end{array}$} & \multicolumn{2}{|c|}{ OR } & \multicolumn{2}{|c|}{$\mathrm{Cl}$} & \multicolumn{2}{|c|}{$P$ value } \\
\hline & $\begin{array}{c}F \\
221\end{array}$ & $\begin{array}{l}M \\
46\end{array}$ & $\begin{array}{c}F \\
111\end{array}$ & $\begin{array}{l}M \\
62\end{array}$ & $F$ & M & $\mathrm{F}$ & M & $\mathrm{F}$ & M \\
\hline \multirow{2}{*}{$\begin{array}{c}\text { Cardiac abnormality } \\
\text { and MVP }\end{array}$} & \multicolumn{2}{|c|}{$\begin{array}{l}154 \\
58 \%\end{array}$} & \multicolumn{2}{|c|}{$\begin{array}{c}89 \\
51 \%\end{array}$} & \multicolumn{2}{|c|}{1.29} & \multicolumn{2}{|c|}{$0.88-1.89$} & \multicolumn{2}{|c|}{0.199} \\
\hline & $\begin{array}{l}126 \\
57 \%\end{array}$ & $\begin{array}{c}28 \\
60 \%\end{array}$ & $\begin{array}{c}53 \\
47 \%\end{array}$ & $\begin{array}{c}36 \\
58 \%\end{array}$ & 1.45 & 1.12 & $\begin{array}{l}0.9- \\
2.3\end{array}$ & $\begin{array}{l}0.5- \\
2.4\end{array}$ & 0.11 & 0.76 \\
\hline \multirow{2}{*}{ Normal } & \multicolumn{2}{|c|}{$\begin{array}{l}113 \\
42 \%\end{array}$} & \multicolumn{2}{|c|}{$\begin{array}{c}84 \\
49 \%\end{array}$} & \multirow{2}{*}{\multicolumn{2}{|c|}{1}} & & & & \\
\hline & $\begin{array}{c}95 \\
43 \%\end{array}$ & $\begin{array}{c}18 \\
40 \%\end{array}$ & $\begin{array}{c}58 \\
53 \%\end{array}$ & $\begin{array}{c}26 \\
42 \%\end{array}$ & & & & & & \\
\hline
\end{tabular}


Table (3): Patients with significant structural heart diseases, compared to normal and MVP.

\begin{tabular}{|c|c|c|c|c|c|c|c|c|c|c|}
\hline \multirow{2}{*}{ Echo study } & \multicolumn{2}{|c|}{$\begin{array}{l}\text { Palpitation } \\
267\end{array}$} & \multicolumn{2}{|c|}{$\begin{array}{c}\text { Control } \\
173\end{array}$} & \multicolumn{2}{|c|}{ OR } & \multicolumn{2}{|c|}{$\mathrm{Cl}$} & \multicolumn{2}{|c|}{$P$ value } \\
\hline & $\begin{array}{c}F \\
221\end{array}$ & $\begin{array}{l}M \\
46\end{array}$ & $\begin{array}{c}F \\
111\end{array}$ & $\begin{array}{l}M \\
62\end{array}$ & $\mathrm{~F}$ & M & $\mathrm{F}$ & M & $\mathrm{F}$ & M \\
\hline \multirow{2}{*}{ Cardiac abnormality } & \multicolumn{2}{|c|}{$\begin{array}{c}78 \\
29 \%\end{array}$} & \multicolumn{2}{|c|}{$\begin{array}{c}58 \\
34 \%\end{array}$} & \multicolumn{2}{|c|}{0.82} & \multicolumn{2}{|c|}{$0.54-1.24$} & \multicolumn{2}{|c|}{0.339} \\
\hline & $\begin{array}{c}61 \\
28 \%\end{array}$ & $\begin{array}{c}17 \\
37 \%\end{array}$ & $\begin{array}{c}31 \\
28 \%\end{array}$ & $\begin{array}{c}27 \\
44 \%\end{array}$ & 0.98 & 0.76 & $\begin{array}{l}0.95- \\
1.63\end{array}$ & $\begin{array}{c}0.35- \\
1.7\end{array}$ & 0.95 & 0.49 \\
\hline \multirow{2}{*}{ Normal and MVP } & \multicolumn{2}{|c|}{$\begin{array}{l}189 \\
71 \%\end{array}$} & \multicolumn{2}{|c|}{$\begin{array}{l}115 \\
66 \%\end{array}$} & \multirow{2}{*}{\multicolumn{2}{|c|}{1}} & & & & \\
\hline & $\begin{array}{l}160 \\
72 \%\end{array}$ & $\begin{array}{c}29 \\
63 \%\end{array}$ & $\begin{array}{c}80 \\
72 \%\end{array}$ & $\begin{array}{c}35 \\
56 \%\end{array}$ & & & & & & \\
\hline
\end{tabular}

Table (4): Percentage of types of echocardiography abnormalities in patients and controls compared to normal echo study.

\begin{tabular}{|c|c|c|c|c|c|c|c|c|c|c|c|}
\hline \multicolumn{2}{|c|}{$\begin{array}{l}\text { Risk factors } \\
\text { (Echo study) }\end{array}$} & palpitation & control & OR & $\mathrm{Cl}$ & $\begin{array}{l}\mathrm{P} \text { - } \\
\text { value }\end{array}$ & $\begin{array}{c}\text { Total } \\
\mathrm{P}\end{array}$ & $\begin{array}{c}\text { Total } \\
\mathrm{C}\end{array}$ & OR & $\mathrm{Cl}$ & $\begin{array}{c}\mathrm{P}- \\
\text { value }\end{array}$ \\
\hline \multirow{2}{*}{ MVP } & fem & $\begin{array}{c}65 \\
29 \% \\
\end{array}$ & $\begin{array}{c}22 \\
19.8 \% \\
\end{array}$ & 1.55 & $0.86-2.8$ & 0.046 & \multirow{2}{*}{$\begin{array}{c}76 \\
28 \%\end{array}$} & \multirow{2}{*}{$\begin{array}{c}31 \\
18 \%\end{array}$} & \multirow{2}{*}{1.82} & \multirow{2}{*}{$1.1-3.0$} & \multirow{2}{*}{0.019} \\
\hline & male & $\begin{array}{c}11 \\
24 \% \\
\end{array}$ & $\begin{array}{c}9 \\
14.5 \%\end{array}$ & 1.77 & $0.6-5.13$ & 0.294 & & & & & \\
\hline \multirow{2}{*}{ M C D } & fem & $\begin{array}{c}47 \\
21 \%\end{array}$ & $\begin{array}{c}29 \\
26.2 \%\end{array}$ & 0.99 & $1.55-1.74$ & 0.97 & \multirow{2}{*}{$\begin{array}{c}62 \\
23 \%\end{array}$} & \multirow{2}{*}{$\begin{array}{c}53 \\
30 \%\end{array}$} & \multirow{2}{*}{0.87} & \multirow{2}{*}{$0.55-1.38$} & \multirow{2}{*}{0.554} \\
\hline & male & $\begin{array}{c}15 \\
32 \% \\
\end{array}$ & $\begin{array}{c}24 \\
38.5 \% \\
\end{array}$ & 0.90 & $0.37-2.2$ & 0.82 & & & & & \\
\hline \multirow{2}{*}{ V/CHD } & fem & $\begin{array}{l}14 \\
6 \% \\
\end{array}$ & $\begin{array}{c}2 \\
1.8 \% \\
\end{array}$ & 4.27 & $0.94-19.4$ & 0.043 & \multirow{2}{*}{$\begin{array}{l}16 \\
6 \%\end{array}$} & \multirow{2}{*}{$\begin{array}{c}5 \\
3 \%\end{array}$} & \multirow{2}{*}{2.38} & \multirow{2}{*}{$0.84-6.75$} & \multirow{2}{*}{0.095} \\
\hline & male & $\begin{array}{c}2 \\
4 \% \\
\end{array}$ & $\begin{array}{c}3 \\
4.8 \% \\
\end{array}$ & 0.96 & $0.15-6.4$ & 0.969 & & & & & \\
\hline \multirow[t]{2}{*}{ Normal } & fem & $\begin{array}{c}95 \\
43 \% \\
\end{array}$ & $\begin{array}{c}58 \\
52.2 \% \\
\end{array}$ & 1 & & & \multirow{2}{*}{$\begin{array}{c}113 \\
43 \%\end{array}$} & \multirow{2}{*}{$\begin{array}{c}84 \\
49 \%\end{array}$} & \multirow{2}{*}{1} & & \\
\hline & male & $\begin{array}{c}18 \\
40 \% \\
\end{array}$ & $\begin{array}{c}26 \\
42 \% \\
\end{array}$ & 1 & & & & & & & \\
\hline Total & & 267 & 173 & & & & 267 & 173 & & & \\
\hline
\end{tabular}

$\mathrm{MVP}=$ mitral valve prolapse, $\mathrm{MCD}=$ myocardial disease, $\mathrm{V} / \mathrm{CHD}=$ valvular or congenital heart diseases, total $\mathrm{P}=$ total patients with palpitations, total $\mathrm{C}=$ total controls, $\mathrm{OR}$ : odd ratio, $\mathrm{Cl}$ : confidence interval.

\section{Discussion}

In our study the palpitation was 4 times more common in females (83\%); this result is slightly more than the ratio described by Summerton et al study (67\%) ${ }^{(15)}$. Palpitations occur frequently in women at all ages, especially during the luteal phase of the menstrual cycle, during pregnancy, and during the perimenopausal period. A correlation between ovarian hormones and occurrence of paroxysmal supraventricular tachycardia has been reported in female patients with normal menstrual cycle ${ }^{(2)}$. Palpitation is frequently reported in cases of mitral valve prolapse, whereas episodes of supraventricular tachycardia reported during pregnancy may be due to mechanical stimuli or to a suggested arrhythmogenic effect of pregnancy. Palpitations during perimenopausal period are usually benign and seem to be related to the increased sympathetic activity ${ }^{(2)}$.

Significant structural cardiac diseases were discovered in 61 (28\%) females compared to $17(37 \%)$ male patients, apparently males with palpitation are more likely to have serious cardiac disorders than females; this is consistent with Weber and Kapoor study which showed that male sex is an independent predictor of a cardiac etiology for palpitation ${ }^{(3,}$ 
$4,16)$. Overall serious structural heart disease found in 78 (29\%) patients with palpitation has no statistical significance compared to 58 (34\%) in the control group, which is relatively a high percent, this is because patients with other presentations like dyspnea and chest pain but without palpitation were included in the control group.

The result of one study ${ }^{(17)}$ of 24-hour ECG monitoring showed that ventricular tachycardia was associated with previous myocardial infarction, idiopathic dilated cardiomyopathy, significant valvular lesions, and hypertrophic cardiomyopathies $^{(18)}$. So diagnosing these disorders in patients with palpitation by conducting echocardiography is important because it may notify serious arrhythmias.

MVP has been found to be the most common valvular cardiac anomaly in developed countries. Hospital based studies, some with flexible criteria for diagnosis put the prevalence of MVP between 5 to 35\%, another study shows the incidence of clinically significant MVP is between 3 to $8 \%$; females affected more than males with 2:1 ratio ${ }^{(19)}$.

In our study MVP was diagnosed in 76(28\%) patients with palpitation compared to $31(17 \%)$ controls ( $P$ value 0.019$)$. It was a significant cause of palpitation in females $(P$ value $0.046)$, but not in males, ( $P$ value 0.29 ). This is consistent with findings of some other studies. In the (study of Framingham offspring), more distinct criteria for diagnosis of MVP were used and showed the incidence of MVP in the general population is about $3 \%$, with no significant difference in men versus women ${ }^{(20)}$. The relatively high percentage of MVP in controls in our study $(17 \%)$ was probably due to inclusion of patients with other symptoms like dyspnea and non specific chest pain in control group. Virtually every type of supraventricular arrhythmias, as well as ventricular premature depolarizations and nonsustained ventricular tachycardia, has been described with MVP and palpitations are nearly ubiquitous in this disorder ${ }^{(21)}$.

Myocardial disorders (including left and right ventricular dilatation, hypertrophy, systolic and diastolic dysfunctions, segmental wall motion abnormalities and ischemic cardiac muscle diseases), were found in 62 (23\%) patients with palpitation, compared to 62 (36\%) controls, ( $P$ value 0.55 ). Palpitation was a less frequent presentation of myocardial disorders and the control group who had complained of dyspnea had more evidence of these disorders. Patents with dilated cardiomyopathy or congestive heart failure rarely feel their heart beat during exertion; instead they have dyspnea as the LV force of contraction is less (7). Palpitation may indicate a hyperkinetic state of the heart (anxiety, anemia, fever, thyrotoxicosis, pregnancy etc). So LV EF is normal or above normal. So presence of palpitation could be an indirect evidence of reasonably good LV function ${ }^{(7)}$. Although palpitations are uncommon in patients with LV dysfunction, they indicate more serious arrhythmia $^{(17) .}$

Significant valvular and congenital heart diseases was found in a small percentage 16 $(6 \%)$ patients with palpitation ( $P$ value 0.095$)$, which was significant in females $(P$ value 0.043 ) but not in males ( $P$ value 0.97 ).

Overall, patients with palpitation were not more likely to have serous abnormal echocardiography than control patients.

\section{Conclusion}

The echocardiography study is not indicated in most patients with palpitation, unless associated with other cardiac symptoms or serious arrhythmias.

Further clinical studies are recommended to correlate the types of palpitations, categories of patients and presence of other diseases with the ECG findings and the echocardiography study in patients with palpitations.

\section{Referrences}

1. Allan $\mathrm{V}$ Abbott, MD. Diagnostic approach to palpitations. Am Fam Physician 2005; 71(4):743-750.

2. Rosano GM, Rillo $M$, Leonardo $F$, et al. Palpitations what is the mechanism and should we treat them. Int J Frrtil women Medicine 1997; 42(2):94-100.

3. Antonio R, Franco $G$, Lennart $B$, et al. management of patients with palpitations: a position paper from the European Heart 
Rhythm Association. europace 2011; 13 : 920-934.

4. Weber BE, Kapor WN. Evaluation and outcomes of patients with palpitation. Am J Med.1996; 100: 138-48.

5. Lok NS, Lue CP. Prevalence of palpitation, cardiac arrhythmias and their associated risk factors. Int J Cardiol.1996; 54(3), 231236

6. Mayou R, Sprigings D, Birkhead J, and Price J. Characteristic of patients presenting to a cardiac clinic with palpitation. Association of physicians 2002: 47.

7. Venkatesan S MD. Palpitation, some observations: expressions in cardiology 2008; 2: 22

8. Whitteridge G. William Harvey and the circulation of the blood. London; MacDonald. 1971: 143.

9. Charles F, Wooley MD. Palpitation brain heart and spirits in the seventeenth century. J R Soc Med.1998; 91: 157-160.

10. Franklin KJ. Some notes on Richard Lower (1663-1692) and his Decorde; London 1669. Ann Med Hist. 1931; 3:599602.

11. Lochen M-L, Snaprud T, Zhang W, et al. Arrhythmias in subjects with and without a history of palpitation: The Tromso study. Eur Heart J. 1994; 15:345-349.

12. Mechael H. Lechman. Palpitations: Regavendra R, Kim A. Practical Cardiology 2008: 36, 40.

13. Paul $\mathrm{H}$, Transer MD. Mitral valve prolapse: The Merk manual of diagnosis and therapy on line medical library 2007:230.
14. Helen R, Jhon PC. Valve disease: Echocardiography a Practical Guide for Reporting. UK 2007, P 52.

15. Summerton N, Mann S, and Rigby A, et al. new onset palpitations in general practice: assessing the discriminant value of items within the clinical history. Winterton medical practice 2001: 115.

16. Mayou R, Sibrigings D, Birkhead J. Characteristics of patients presenting to a cardiac clinic with palpitations.Q J Med.2003;96:115-23.

17. Wolfe RR, Driscoll DJ, Gersony WM, et al. arrhythmias in patients with valvular aortic stenosis, valvular pulmonary stenosis, and ventricular septal defect. Results of 24 hour ECG monitoring. Circulation 1993; 87(8):19-101.

18. Allan V, Abbott MD. Diagnostic approach to palpitations. Am F Physician 2005; 71(4): 743-750.

19. Manoria PC, Trivedi SK. Mitral valve prolapse: Satpathy M, Mishra BR. Clinical diagnosis of congenital heart diseases 2008, p 60.

20. Playford and Weyman. Mitral valve prolapse: time for fresh look. Reviews in cardiovascular medicine 2001; 2(2):73-81.

21. Peter Z, Mark E, Josiphson. Evaluation of patients with palpitation. The New England $\mathrm{J}$ of medicine 1998;19: 383.

22. Duren DR, Becker AE, Dunning AJ. Long term follow up of idiopathic mitral valve prolapse in 300 patients: a prospective study. J Am Coll Cardiol. 1988; 11: 42-7. 